\title{
ANTIBACTERIAL EFFECT OF VIRGIN COCONUT OIL ON (ACTINOMYCES SP.) THAT CAUSES DENTAL BLACK STAIN IN CHILDREN
}

\author{
PRISCILLA LAVINE, EVA FAUZIAH*, MOCHAMAD FAHLEVI RIZAL, SARWORINI BAGIO BUDIARDJO
}

Department of Pediatric Dentistry, Faculty of Dentistry, Universitas Indonesia, Jakarta, Indonesia. Email: eva_dens@yahoo.com

Received: 18 October 2017, Revised and Accepted: 20 November 2017

\section{ABSTRACT}

Objective: This study aimed to assess the effectiveness of virgin coconut oil (VCO) as a natural antibacterial agent to reduce the viability of the chromogenic bacteria Actinomyces sp., which causes dental black stains.

Methods: Actinomyces sp. was isolated from the saliva of a child diagnosed with black stain. Each streak of bacteria was cultured on a selective medium Actinomyces agar and confirmed visually and through a gram staining procedure. Each bacterial culture was exposed to VCO in concentrations of $12.5 \%, 25 \%, 50 \%$, and $100 \%$. Afterward, viability testing with a methyl-thiazolyl-tetrazolium assay was conducted, and the results were read using an enzyme-linked immunosorbent assay reader.

Results: The reduction of bacterial viability of Actinomyces sp. showed a significant difference between the negative control group and the groups treated with various concentrations of VCO $12.5 \%, 25 \%, 50 \%$, and $100 \%$.

Conclusion: The minimum concentration of VCO necessary to kill Actinomyces sp. is VCO $12.5 \%$.

Keywords: Actinomyces sp., Dental black stain, Virgin coconut oil.

(C) 2018 The Authors. Published by Innovare Academic Sciences Pvt Ltd. This is an open access article under the CC BY license (http://creativecommons. org/licenses/by/4. 0/) DOI: http://dx.doi.org/10.22159/ajpcr.2018.v11i2.23199

\section{INTRODUCTION}

Dental black stain is a type of extrinsic discoloration related to clinical and esthetic problems that can occur at any age on primary and permanent teeth [1]. This type of pigmentation is a special form of dental plaque that contains insoluble iron salt and a high content of calcium and phosphate. The black material that is seen is a ferric salt (ferric sulfide) formed by the reaction between hydrogen sulfide that is produced by bacterial action and the iron present in saliva or gingival exudates [1,2]. Chromogenic bacteria such as Actinomyces sp. and Prevotella melaninogenica, which produce black color pigmentations, are suspected to be the cause of the staining. Of the bacteria that can be isolated from black stains, $90 \%$ are facultative aerobic and anaerobic Gram-positive rods, which are identified as Actinomyces sp. [3]. Black stain is defined as a thin, black deposit in a narrow line above the free gingiva. It can also present as distinct, dark dots that extend beyond the cervical third of the crown, sometimes affecting pits and fissures [4]

A previous study was conducted in 2012 on saliva samples from 15 children with black stain and saliva samples on 15 children without black stain in Jakarta. This study showed that the quantity of Actinomyces sp. in the saliva of children with black stain is higher than it is in children without black stain. However, it was also found that the quantity of Actinomyces sp. in the saliva of children did not differ significantly between those with black stain and those without black stain [5].

The cleaning procedure required for the treatment of black stain can be challenging to dentists, especially when the black stain is deposited on pit and fissure areas of the tooth. Even when removal through ultrasonic scaling and polishing with a rubber cup and fluoride pumice have been performed, black stain tends to recur, regardless of the patient's good oral hygiene [3]. Therefore, an antibacterial agent is required to inhibit the growth of the chromogenic bacteria that cause black stain.
Antibacterial mouthrinse has been considered an effective method in controlling dental plaque. These antibacterial agents may be derived from chemical compounds or natural ingredients. Evidence in the dental literature supports chlorhexidine as the gold standard of biofilmpreventing antiplaque and antigingivitis agents [6]. An alternative antibacterial agent can be obtained from coconuts, allowing for the use of natural ingredients to promote dental health. Virgin coconut oil (VCO) is taken from the flesh of fresh coconuts (Cocos nucifera) without the application of heat, a process which avoids any alteration of the oil so that the main components such as vitamins, antioxidants, and polyphenols remain in the VCO. Unlike any other cooking oil, VCO does not undergo chemical refining, bleaching, and deodorizing process. VCO appears as clear oil, which has a distinct coconut scent $[7,8]$. A number of fatty acids were detected within the oil, namely caproic, caprylic, capric, lauric, myristic, palmitic, stearic, oleic, and linoleic acid. However, lauric acid has highest percentage of about $47 \%$ in VCO [8]. Lauric acid, the main component of VCO, has antibacterial, antivirus, and antiprotozoal effects. Lauric acid can kill gram-positive bacteria by damaging the bacterial cell membrane, resulting in membrane lysis and inhibited bacterial growth $[9,10]$.

Studies that focus on black stain and its treatment are rarely found in the dental literature. The aim of this study was to assess the antibacterial effects of various concentrations of VCO on the viability of Actinomyces sp., which causes dental black stain in children.

\section{METHODS}

This study was an in vitro laboratory experiment that tested the viability of Actinomyces sp. after the administration of VCO in various concentrations. With approval from the ethical committee of the Faculty of Dentistry Universitas Indonesia, the subjects, children diagnosed with dental black stain, were identified. The inclusion criteria were as follows: children aged 4-11 years with a good oral condition, the presence of black stain on at least 10 teeth enamel surfaces, and 
parental consent. The exclusion criteria included poor oral hygiene, high incidence of caries (deft $>5$ ), and subjects under medical care or taking medicine. A sampling of saliva was performed after parents signed the informed consent.

\section{Saliva collection}

Subject was aksed to sit in upright position to collect unstimulated saliva at the bottom of the mouth for $1 \mathrm{~min}$. The collected saliva was then spit into a centrifuge tube.

\section{Actinomyces sp. colonization and identification; viability test using an methyl-thiazolyl-tetrazolium (MTT) assay}

The experimental and laboratory study with sample measurement used the Federer formula to obtain 3 samples. Then, duplo was conducted so that each treatment provided 6 samples. The bacterial suspension was transferred to Actinomyces agar, which was used as a selective medium for Actinomyces sp. The agar plate was placed inside an anaerobic jar that contained $80 \% \mathrm{~N}_{2}, 10 \% \mathrm{H}_{2}$, and $10 \% \mathrm{CO}_{2}$ and was incubated for $48 \mathrm{~h}$ at $37^{\circ} \mathrm{C}$. The identification of Actinomyces sp. culture was performed by visual inspection and a gram staining procedure. Following identification, $200 \mathrm{uL}$ of bacteria was suspended on a 96-well plate and incubated in an anaerobic setting for $20 \mathrm{~h}$ at $37^{\circ} \mathrm{C}$.

While the bacteria were in the incubator, a VCO testing solution was created in the following concentrations: $12.5 \%, 25 \%, 50 \%$, and $100 \%$. Dilution of the VCO was completed using a phosphate buffer solution. Then, the VCO solutions were homogenized to obtain a homogenous solution.

After $20 \mathrm{~h}$, the $200 \mathrm{uL}$ of Actinomyces sp. suspended on the 96-well plates were exposed to $100 \mathrm{uL}$ of VCO in various concentrations. Bacteria exposed to the positive control $(0.2 \%$ chlorhexidine gluconate $)$ and the negative control (without testing material) were also prepared. Then, the bacteria were incubated for $60 \mathrm{~min}$ in an anaerobic setting at $37^{\circ} \mathrm{C}$. Finally, an MTT solution was poured into each well of the tested material and the tested material solutions were incubated for $3 \mathrm{~h}$. The results of the MTT testing were read using an enzyme-linked immunosorbent assay reader at wavelength of $490 \mathrm{~nm}$

\section{Statistical analysis}

One-way analysis of variance (ANOVA) tests were used to compare the bacterial viability of Actinomyces sp. (based on optical density [OD] measures) treated with various VCO concentrations of $12.5 \%, 25 \%$, $50 \%$, and $100 \%$, a positive control ( $0.2 \%$ chlorhexidine gluconate), and a negative control (without testing material) with a significance value of $\mathrm{p}<0.05$

\section{RESULTS}

Data normality was tested using the Shapiro-Wilk test, and the data's score showed a normal distribution. The data for Actinomyces sp. after the administration of various concentrations of VCO were analyzed using one-way ANOVA to identify any discrepancies between each bacterial viability score.

Table 1 shows the differences in the Actinomyces sp. viability scores after the administration of the antibacterial agent in various concentrations. The ANOVA significance was calculated as $0.003(\mathrm{p}<0.05)$, and at least two groups had significantly different viability means. Since the results of the one-way ANOVA test revealed significant differences, post hoc testing was conducted to determine which intergroup had different means of viability scores.

Table 2 shows the results of the post hoc analysis of Actinomyces sp. Statistically significant differences in the Actinomyces sp. viability scores were found between the negative control group and the positive control $(0.2 \% \mathrm{Chx})$ group, the negative control group and the group treated with VCO $100 \%$, the negative control group and the group treated with VCO 50\%, the negative control group and the group treated with VCO 25\%, and the negative control group and the group treated with VCO 12.5\% (p<0.05).

\section{DISCUSSION}

This study was conducted to identify the effect of VCO as an alternative antibacterial agent on the viability of Actinomyces sp., which causes dental black stain in children. In this in vitro laboratory experiment, VCO that was $61.07 \%$ lauric acid [11] was used as antibacterial agent in the following concentrations: $12.5 \%, 25 \%, 50 \%$, and $100 \%$. Lauric acid is a powerful Gram-positive bacteria destroyer, whose non-polar properties enable it to penetrate the cell membrane, destroying the phospholipid bilayer and resulting in membrane lysis [12].

A cytotoxicity assay can be used to assess the antibacterial effects of certain substances. The cytotoxicity testing used in this study was an MTT assay, which is a standard colorimetric laboratory test that measures viable cells and is stated in OD [13].

In this study, exposure to VCO was completed during the 20-h biofilm formation phase (active accumulative phase), a process which was performed in previous studies in which active growth occurred, enabling antibacterial agents to kill bacteria. In the 4-h biofilm formation phase (adhesive phase), exposure to antibacterial agents did not reveal bacterial growth, and bacterial viability was not detected. In the 24-h biofilm formation phase (maturation phase), bacterial growth slows, increasing the formation of extracellular polysaccharides and the bacteria's resistance to antibacterial agents [14]

The statistical analysis (Table 1) shows that each increase in VCO concentration causes a decline in the bacterial viability value compared to the negative control where there is no testing material. Compared to the positive control, which was a commercially available $0.2 \%$ chlorhexidine gluconate mouthrinse, various concentrations of VCO showed the same effect as the gold standard antibacterial agent.

The statistical analysis (Table 2) shows a significant difference in the bacterial viability of Actinomyces sp. between the negative control group and the groups treated with VCO 12.5\%, 25\%, 50\%, and 100\%. Therefore, in this study, the minimum concentration of VCO necessary to kill Actinomyces sp. was VCO $12.5 \%$.

\section{CONCLUSION}

Based on our findings, it is concluded that each progressive augmentation of $\mathrm{VCO}$ concentrations $12.5 \%, 25 \%, 50 \%$, and $100 \%$ cause reduction in the bacterial viability of Actinomyces sp. The reduction of bacterial viability of Actinomyces sp. is significantly different between a negative control group and groups treated with VCO. The minimum concentration of VCO necessary to kill Actinomyces sp. is VCO 12.5\%.

This study is preliminary and involves direct contact between the antibacterial solutions and Actinomyces sp., so it does not accurately describe the situation in an actual oral cavity. Therefore, further in vivo study is needed to assess the antibacterial effect of VCO on dental black stain in conditions that resemble the actual oral environment.

Table 1: Differences in Actinomyces sp. viability scores after administration of VCO in various concentrations

\begin{tabular}{llll}
\hline Treatment group & $\mathbf{n}$ & $\begin{array}{l}\text { Bacterial } \\
\text { viability (OD) } \\
\text { means } \pm \text { SD }\end{array}$ & p value \\
\hline Negative control & 3 & $0.221 \pm 0.003$ & $0.003^{*}$ \\
Positive control (0.2\% Chx) & 3 & $0.193 \pm 0.008$ & \\
VCO 100\% & 3 & $0.195 \pm 0.006$ & \\
VCO 50\% & 3 & $0.195 \pm 0.014$ & \\
VCO 25\% & 3 & $0.190 \pm 0.004$ & \\
VCO 12.5\% & 3 & $0.193 \pm 0.003$ & \\
\hline
\end{tabular}

One way ANOVA test; * significant score based on $P<0.05$, OD: Optical density,

SD: Standard deviation, VCO: Virgin coconut oil 
Table 2: Post hoc analysis of differences in Actinomyces sp. viability scores in treatment intergroups

\begin{tabular}{ll}
\hline Treatment group & Difference in viability means \\
\hline Negative control versus positive control $(0.2 \%$ Chx $)$ & 0.271 \\
Negative control versus VCO 100\% & 0.253 \\
Negative control versus VCO 50\% & 0.255 \\
Negative control versus VCO 25\% & 0.305 \\
Negative control versus VCO 12.5\% & 0.019 \\
Positive control $(0.2 \%$ Chx) versus VCO 12.5\% & 0.018 \\
VCO 100\% versus 12.5\% & 0.001 \\
VCO 50\% versus 12.5\% & 0.002 \\
VCO 25\% versus 12.5\% & 0.009 \\
\hline Posthoc & 0.000 \\
\hline
\end{tabular}

Post hoc Bonferroni test; significant score based on $P<0.05$, VCO: Virgin coconut oil

\section{ACKNOWLEDGMENT}

The publication of this manuscript is supported by Universitas Indonesia in 2017.

\section{CONFLICT OF INTERESTS}

The authors declare that they have no conflict of interests.

\section{REFERENCES}

1. Li Y, Zhang Q, Zhang F, Liu R, Liu H, Chen F. Analysis of the microbiota of black stain in the primary dentition. PLoS One 2015;10:1-13.

2. França-Pinto CC, Cenci MS, Correa MB, Romano AR, Peres MA, Peres KG, et al. Association between black stains and dental caries in primary teeth: Findings from a Brazilian population-based birth cohort. Caries Res 2012;46:170-6.

3. Ronay T, Attin V. Black stain-a review. Oral Heal Prev Dent 2011;9:37-45

4. Zyla M, Kawala T, Antoszewska-Smith B, Kawala J. Black stain and dental caries: A review of the literature. Biomed Res Int 2015;2015:1-6.

5. Indiarti IS, Rustan Y, Budiardjo SB. Identification quantity of Actinomyces in children saliva with black stain in tooth enamel surface. Int J Clin Prev Dent 2013;9:163-8

6. Ronanki S, Kulkarni S, Hemalatha R, Kumar M, Reddy P. Efficacy of commercially available chlorhexidine mouthrinses against specific oral microflora. Indian J Dent Res 2016;27:48-53.
7. Suraweera RK, Pasansi HG, Herath HM, Wickramaratne DB, Sudeshika SH, Niyangoda D, et al. Formulation and stability evaluation of ketoprofen loaded virgin coconut oil based creamy emulsion. Int J Pharm Pharm Sci 2014;6:112-6.

8. Azimatul N, Maidin $\mathrm{QH}, \mathrm{Ahmad}$ N. Protective and antidiabetic effects of virgin coconut oil (VCO) on blood glucose concetration in alloxan induced diabetic rats. Int J Pharm Pharm Sci 2015;7:57-60.

9. Loung FS, Silalahi J, Suryanto D. Antibacterial activity of enzymatic hydrolyzed of virgin coconut oil and palm kernel oil against Staphylococcus aureus, Salmonella thypi and Escherichia coli. Int J Pharm Technol Res 2014;6:628-33.

10. Peedikayil FC, Sreenivasan P, Narayanan A. Effect of coconut oil in plaque related gingivitis-a preliminary report. Niger Med J 2015;56:143-7.

11. Mutia. Mutia Virgin Coconut Oil; 2010. Available from: http://www.mutiavco.com/produk-mutia-vco.

12. Veronica O. Extraction of lauric acid from coconut oil, its applications and health implications on some microorganisms. Afr J Educ Sci Technol 2016;3:144-7.

13. Ahmadian S, Barar J, Saei AA, Fakhree MA, Omidi Y. Cellular toxicity of nanogenomedicine in MCF-7 cell line: MTT assay. J Vis Exp 2009;26:2-4

14. Kostakioti M, Hadjifrangiskou M, Hultgren SJ. Bacterial biofilms: Development, dispersal, and therapeutic strategies in the dawn of the postantibiotic era.Cold Spring Harb Perspect Med 2013;3:1-23. 